\title{
VISION DE LA REALIDAD EN EL TEATRO CUBANO
}

\author{
POR \\ FRANK DAUSTER \\ Rutgers University
}

Uno de los elementos formales de mayor trascendencia en el teatro cubano moderno es la insistencia en experimentar con las estructuras de la tragedia clásica. Se han discutido las relaciones formales de Medea en el espejo, de José Triana, con la Electra Garrigó, de Virgilio Piñera, dos obras cuyos modelos son obras griegas específicas, y hay otras notables tentativas en el mismo sentido, como, por ejemplo, Los siete contra Tebas, de Antón Arrufat, o La muerte del Ñeque, otra obra de Triana, cuyas semejanzas con las formas trágicas son igualmente importantes, si bien menos obvias. Tienen en común también el hecho de estar ubicadas en el período de la República, y se ha aventurado la hipótesis de que esta concentración en formas dramáticas aparentemente desligadas del mundo cubano actual se podría explicar en términos del deseo de comprender y a la vez de conferir algún significado a un período histórico nada glorioso.

Pero pocos comentaristas se han fijado en que esta concentración en las formas trágicas va acompañada de otro aspecto obsesivo del teatro cubano del siglo xx: el submundo habanero del hampa, ambiente que fascina a muchos dramaturgos, en especial a José Brene (1927) y a Carlos Felipe (1913-1975). En muchos de los mismos autores, aunque quizá de manera menos obvia, hay un movimiento hacia la revalorización de las formas saineteras, tentativa claramente relacionada con la insistencia formal en la tragedia y la obsesión temática con los peores aspectos de la malhadada República, y que tiene claras semejanzas causales con la reciente revalorización del sainete rioplatense. Tanto Brene, quien fue durante años el principal vocero de la Revolución entre los dramaturgos cubanos, y Felipe, con Virgilio Piñera, una de las dos figuras dominantes del teatro prerrevolucionario, escribieron después de la Revolución obras cuyo per- 
sonaje principal es Alejandro Yarini, el legendario chulo de comienzos de siglo. El mundo de estas obras es inconfundiblemente el mismo de Medea en el espejo y La muerte del Ñeque, de Triana. Además, las cuatro se estrenaron durante un lapso breve: Medea, escrita en 1959, es de 1960; el $\tilde{N} e q u e$ se representó por primera vez en 1963 y El gallo de San Isidro en 1964. Réquiem por Yarini fue escrita en 1960 y estrenada en 1966. Salta a la vista que hay en ese mundo sórdido algo que despierta resonancias en los tres dramaturgos casi en el mismo momento.

A pesar de que son posteriores a las obras de Triana, primero veremos las obras de Brene y Felipe. Tienen en común el escenario del barrio humilde, pero en la obra de Brene hay también un elemento sociopolítico avasallador. El mismo autor lo reconoce al decir:

Creo que todo teatro, por malo que sea, es teatro social. Ahora bien, hay teatro anti-social y teatro pro-social. Pero siempre el teatro es social. Toda obra teatral tiene por fuerza que situar personajes en determinado momento histórico y en determinada sociedad. Aunque el dramaturgo se empeñe en pro o en contra, siempre hace teatro social. No le queda más remedio '.

Todo esto es absolutamente cierto, y hasta se podría afirmar que toda obra de teatro es un comentario al mundo en que está situada, pero la concentración de Brene va mucho más allá. Sus obras tienen una tendencia muy fuerte, mucho más fuerte de lo que indican sus palabras citadas, a respaldar, de un modo abierto, los ideales revolucionarios. Se ve esto de manera muy obvia en su obra más conocida, Santa Camila de La Habana Vieja, cuya acción pasa en la consabida casa de vecindad o solar. El protagonista, Nico, y sus amigos no son más que delincuentes de poca monta; a Nico lo mantiene Camila con lo que gana como santera. El ambiente de la obra es de relajo erótico casi sin freno. No obstante, la atmósfera es menos de prostitución o criminalidad que de sencilla flojera moral. Siguiendo la política oficial de la época, la obra condena la santería, y todo el enfoque es más bien propagandístico que dramático. Se contrasta la incapacidad de Camila para comprender el proceso revolucionario con la devoción abnegada, aunque de cartón, de Leonor, a quien llamó Calvert Casey, en una reseña publicada en Diario de la tarde, 24 de agosto de 1962, «modelo sin vida ni humor».

Con Santa Camila, por primera vez una obra cubana atrajo un público de más de veinte mil espectadores; es también el primer drama que presenta

' Contestación a la encuesta sobre «El nuevo teatro cubano», La Gaceta de Cuba (II, 19, 3 junio 1963), p. 4. 
una historia ocurrida «después» de la Revolución ${ }^{2}$. Expresó algo exageradamente su alta apreciación del drama Manuel Galich, al decir «Asocio, en mi mente, el estreno de Santa Camila con el de M'hijo el dotor, de Florencio Sánchez, en el Buenos Aires de 1903. Porque, en ambos casos, un autor rompía en una noche, con un estreno, su cuasi anonimato y se colocaba a la cabeza de los dramaturgos de su país y de su tiempo» ${ }^{3}$. Tales euforias desmedidas y el extraordinario éxito de taquilla quedaron algo moderados por la incomodidad de algunos críticos frente al hecho innegable de que el triunfo de la Revolución se estaba identificando con la conversión política de una santera de muy dudosa moral sexual. Pero en términos dramáticos la obra sufre de una debilidad más grave: la transformación abrupta de Nico ocurre totalmente fuera de escena. De sinvergüenza casi sin cualidades que lo rediman súbitamente, se convierte en joven idealista y altruista, lleno del progresivo espíritu revolucionario. La explicación presunta es que la Revolución es capaz de efectuar tales cambios drásticos. Así sea, pero como «figura dramática» es muy poco convincente, sobre todo hacia el fin del drama, donde rompe a hablar como profesor de dialéctica, en contraste con el sabor popular del habla de Camila y los otros habitantes del solar.

El gallo de San Isidro es Alejandro Yarini, personaje histórico asesinado en 1910, probablemente a instancias de corrompidas figuras altas del Gobierno, en connivencia con los chulos franceses que dominaran antes el negocio de la prostitución. El Yarini de Brene es acaudalado político militante en el Partido Conservador. Entra en un acuerdo con los franceses, en un esfuerzo por romper el poderío del corrompido Gobierno Liberal que protegía a los dueños de la prostitución. El propósito de la obra es sobradamente claro:

CLiente 3: Y yo que creía que la vida del Yarini fue alegre y que era el emperador de los chulos cubanos, el maestro.

CRISANTEMO: No, mi hijito fue lo mismo que todos los chulos del mundo, un equivocado, un bambollero.

Prostituta 5: ¿Y cuándo la vida de nosotros ha sido alegre? Bueno, en las novelitas de a diez kilos (Teatro, p. 196).

La obra tiene diversos elementos técnicos intrigantes, sobre todo los desplazamientos temporales, el empleo de las máscaras y la obra dentro de la obra. Comienza la acción en un burdel una noche desocupada de 1955; las aburridas pupilas y sus igualmente hastiados clientes intentan

\footnotetext{
${ }^{2}$ Rine Leal, En primera persona (La Habana: Instituto del Libro, 1967), p. 184.

3 «Prólogo», José R. Brene, Teatro (La Habana: Edit. Letras Cubanas, 1982), p. 6.
} 
persuadir a la madama Elena de que les narre su amorío con el legendario Yarini. Pero ella los convence de que entre todos representen la famosa historia, y hasta recluta a dos policías exigiendo el pago de sus sobornos y algunos chulos rivales que entran en busca de reyertas. Con esto, la escena pasa a 1908; la actriz que representa a Elena se quita la máscara de vieja y estamos en el mundo de Yarini. Se efectúa todo esto de manera muy eficaz, con el desplazamiento repetido al comienzo de cada acto, de modo que comentarios pasajeros en 1955 ilustran la situación de 1910, a la vez que comentan sardónicamente problemas sociales modernos. Es de lamentar que los parlamentos de Brene sean tan artificiosos que es realmente imposible tomar la obra tan en serio como probablemente merece.

Como Santa Camila de La Habana Vieja, El gallo de San Isidro es obra esencialmente política, cuyo propósito es desacreditar la República prerrevolucionaria. Como dice Elena, la prostituta amante de Yarini: «Nosotras somos reflejo de lo que pasa de Palacio para abajo. Hijas mías, Cuba ha sido un gran burdel desde que le dijeron que era libre» ${ }^{4}$. El mito de Yarini queda desinflado; se le presenta como una víctima más de los extranjeros, que son el verdadero Gobierno cubano. Mientras comienzan a comprender esto, las prostitutas de 1955, mediante la representación de la historia, empiezan también a percibir su propia condición de oprimidas. Desacreditar a Yarini, desromantizar su mito, son formas de demostrar que la República entera estaba corrompida y que sólo a través de la Revolución se iba a poder poner un fin a la desastrosa situación. Pero la obra sufre de algunos contrastes y problemas internos que la debilitan seriamente. El diálogo es realmente intolerable; cada personaje, por analfabeto que sea, habla un español tan hinchado que se vuelve risible. No es lo mismo, por ejemplo, el diálogo poético de Winterset, de Maxwell Anderson, donde tiene la función de ahondar en los personajes, de penetrar más allá de la superficie, para llegar a sus sentimientos verdaderos. El diálogo de Brene nunca es de los puntos más fuertes de sus obras, y cualesquiera que fuesen sus razones por haber empleado tales altisonancias en una obra poblada de prostitutas y chulos, resulta contraproducente. Los personajes resultan poco convincentes, títeres del dramaturgo, en una obra cuyos obvios propósitos políticos requieren que la obra no caiga en tales extremismos. Parece irónico en una obra cuyo propósito es la desmitificación, y aún más, la desromantización de Yarini, que su relación con Elena se nos presente de una forma tan romántica que resulta dramáticamente destructiva.

Nació Carlos Felipe de familia humilde, precisamente en San Isidro,

\footnotetext{
${ }^{4}$ Teatro, p. 197.
} 
el viejo barrio «alegre» de Yarini, y la acción de varias de sus obras pasa en tales lugares. Se escribió Réquiem por Yarini en 1960, y como es el caso con las dos obras mencionadas de Brene, la superstición y la santería desempeñan un papel importante en la vida de sus personajes. Tanto es así, que el Yarini de Felipe se afilia a un grupo de ñáñigos por el apoyo político y profesional que le brindará. Más que político ambicioso, aquí Yarini es hombre que se vanagloria de su dudosa prófesión. En las dos obras, el fondo del asesinato de Yarini es la campaña pro moral pública emprendida por el Gobierno para salvar las apariencias; sencillamente, los líderes gubernamentales decretaron la muerte de Yarini porque les estorbaba. Igualmente, en las dos obras Yarini se enamora de una de las prostitutas que lo mantiene. Pero esta versión de Yarini es muy diferente de la de Brene. Sobre todo los detalles de la caída de Yarini han sido alterados drásticamente. Donde el protagonista de Brene muere por su amor por una prostituta que se niega a acostarse con él, el de Felipe cae porque se enamora de Lotot, la amante de Yarini, el rival de éste. Como el honor del chulo no permite que su rival quiera a una de sus mujeres, Yarini pierde a Lotot en el juego, lo cual conduce, a su turno, a la muerte de Yarini en un duelo mano-a-mano provocado por su rival.

Felipe no logra purificar su drama de trasnochadas actitudes románticas más de lo que lo pudo hacer Brene. Además del pintoresco triángulo, de pura estirpe sainetera, aparece un bizantino personaje, conocido como la Dama del Velo, desconocida mujer de aparente alcurnia y posición social. Dice que visita a Yarini porque ha tenido tantas noticias de él, y después de tener que esperar largamente mientras que Yarini se ocupa con otros asuntos, la Dama le hace algunas declaraciones bastante abiertas y se marcha. La Dama no tiene otra función que subrayar el magnetismo sexual de Yarini, que hechiza a mujeres de todo rango y clase social, pero es más bien estorbo dramático que otra cosa, y todo el concepto y su realización son arrolladoramente románticos. Lo mismo podríamơs decir de la salida de Yarini con la Macorina. Fue ésta prostituta famosa de los días tempranos de la República, y vivía todavía cuando se escribió la obra. Afirma José Escarpanter: «Felipe me explicó que daba por muerta en aquella época a la Macorina para completar con ella el mito de la vida galante de los principios del siglo» ${ }^{5}$. Dentro de la obra, la Macorina funciona simultáneamente como combinación de la muerte y el espíritu reencarnado del amor romántico. Ha dicho Escarpanter que «el héroe

${ }^{5}$ José A. Escarpanter, «Réquiem por Yarini, de Carlos Felipe: una tragedia cubana», en Alberto Gutiérrez de la Solana y Elio Alba Bufill, eds., Festschrift José Cid Pérez (Nueva York: Senda Nueva de Ediciones, 1981), p. 108. 
trágico muere, pero tras las puertas del misterio le aguarda la Macorina para la glorificación y la plenitud de un amor que no pudo consumarse en esta tierra bajo el signo de la carne, porque los tiempos históricos de la pareja no habían coincidido» ${ }^{6}$.

A Carlos Felipe le resultaba imposible deshacerse de tales clisés teatrales, puesto que su propósito dramático estaba hondamente arraigado en otro clisé: el magnetismo masculino y la nobleza espiritual de Yarini.

No creerán que he tomado en serio los ladridos de Lotot. Mientras él vociferaba pensaba yo en la nobleza de la misión del souteneur. Poseemos el instinto de la belleza femenina y el de la capacidad de la mujer para el amor; buscamos los más altos exponentes de estos dones de la naturaleza; los sustraemos del egoísmo burgués del matrimonio y, dadivosamente, a cambio de una módica cuota indispensable, los ponemos al alcance de los hombres todos, para que calmen su sed de amor y de belleza. El souteneur tiene mucho de un dios que sintiera compasión por los hombres ${ }^{7}$.

Resulta extremadamente difícil tomar tal pasaje extraordinario como otra cosa que el cinismo más descarado o la expresión de una actitud machista arquetípica. Siempre es peligroso encontrar en los parlamentos de un personaje la filosofía del autor, pero este parlamento es realmente clave dentro del desarrollo de la obra. Ni puede ser la expresión desvergonzada de un cínico; Yarini está abiertamente idealizado. Salta a la vista que Felipe lo concibió como personaje simpático y no solamente como portavoz de actitudes machistas. Su creador buscó revestirle de dignidad, de un sentimiento de humanidad, de un destino trágico, para conferirle algún significado duradero a lo que de otra manera sería un período nacional incomprensible. Rine Leal señala la importancia de congelar el pasado, para así recuperarlo en el teatro de Felipe.

Yo diría que el tema esencial del teatro de Carlos Felipe es el deseo de recuperar el ayer, lograr su fijeza, congelar el tiempo. Sus personajes llevan consigo la herida del pasado, una cicatriz imborrable que los fuerza a volver atrás el rostro a pesar del riesgo de morir. Tal es la prohibición que Yarini desobedece, y cuando se vuelve para contemplar a la Santiaguera está en realidad sellando su abrazo con la muerte que desciende bajo la forma de la Macorina. Ese anhelo de detener el paso de los años, seleccionar un trozo del pasado y vivir de nuevo... encubre una idea que redondea la concepción del mundo dramático de Carlos: el autorreconocimiento.

Hay un momento en que sus personajes están tocados por esa gracia

${ }^{6}$ Op. cit., p. 105.

7 Carlos Felipe, Teatro (La Habana: UNEAC, 1967), p. 233. 
humana que es el amor y luego el tiempo los lanza a un lado para dejar en sus mentes como un estremecimiento que los angustia. Es el momento en que existieron de verdad, que rozaron la vida, en que el mundo cobró para ellos un sentido vital. Al recuperar ese pasado sucede un milagro: la imagen se desvanece, se vuelve polvo y cenizas... ${ }^{8}$

Es cierto que Felipe buscaba crear algo muy parecido a la epifanía trágica en algunas, cuando menos, de sus obras, y notablemente en Réquiem por Yarini. Este congelar el pasado para hurgar en él, a la búsqueda de la percepción trágica, logra conferir a veces el sentimiento de dignidad trágica que tan desesperadamente intentaba crear el autor. Como Brene, quien fue durante años marinero y sabía poco de teatro, el autodidacta Felipe tenía graves problemas con el diálogo. Por ejemplo, Leal dijo que las obras de «Carlos Felipe y Paco Alfonso (para tomar dos casos situados en los extremos de una sensibilidad) ilustran perfectamente la baja calidad literaria de los autores cubanos» ${ }^{9}$. Sus personajes son víctimas de las emociones más superficiales y trilladas y la caracterización tiende a veces a la poca profundidad, lo cual es lamentable, ya que por momentos la concepción dramática era muy prometedora. Sí logró hacer de Yarini una figura dramática de ciertas dimensiones. Quizá el impacto mayor de su teatro, muy visible en Yarini, es la insistencia en la cubanía de tema, ambiente y actitud.

El teatro de José Triana (1933) también está arraigado en esta búsqueda de la cubanía esencial, pero profundiza mucho más en el problema. Se concentra en lo irracional y lo incoherente del comportamiento humano, y en la violencia que percibe en el meollo de la psicología cubana. Se ahonda en sus personajes para escudriñar a la humanidad en sus momentos más críticos, para subrayar las realidades más profundas que yacen por debajo de la aparente existencia cotidiana. Considera Triana que el teatro es esencialmente trágico, porque presenta a los personajes en el momento agudo de escoger frente a las alternativas más desesperadas. Al rechazar el realismo convencional, Triana intenta elevar la realidad a un plano más poético, sin embellecerla y sin pasar por alto sus inferencias más devastadoras. A la vez, éste es un teatro arraigado en la realidad cubana, en un sentido crítico de lo que constituye esa realidad, el mismo sentido crítico que condujo al autor a alejarse de la corrupción política y social de los años anteriores a 1958. Sus creaciones están ancladas en la precariedad de la realidad cubana. Vienen de un mundo urbano, y especialmente de sus infraestructuras, el mundo de mendigos, vagos, prostitutas y el siempre

8 «Un Carlos 1lamado Felipe», en En primera persona (La Habana: Instituto del Libro, 1967), pp. 188-201; la cita corresponde a la p. 195

${ }^{9}$ En primera persona, «Actuales corrientes en el teatro cubano», p. 94. 
caudillo político. Sus relaciones humanas están controladas por el desorden, por la falta de un sentido orgánico del movimiento de la vida, por un cosmos que parece estar remoto del control humano.

El éxito internacional casi sin paralelo de La noche de los asesinos y el silencio posterior hasta muy recientemente de Triana, han conducido a ciertas anomalías curiosas en la crítica de su obra. En primer lugar, la gran mayoría trata Asesinos, e ignora casi enteramente las obras anteriores. Segundo, las interpretaciones de la obra oscilan de una manera realmente fascinante. Se ha visto como crítica a las decadentes estructuras familiares de la Cuba prerrevolucionaria, como expresión del mito de la violencia subyacente a toda dimensión de la vida cubana, como reflejo de formas emotivas universales y hasta como manifestación de los latentes sentimientos contrarrevolucionarios del autor. Por ejemplo, Román de la Campa rechaza la opinión ampliamente extendida de que La noche de los asesinos representa una culminación de tendencias visibles de modo importante en las obras tempranas, añadiendo que en Cuba «este autor ha sido percibido por una visión más integral de su obra. Desde que se estrena Medea en el espejo, en 1960, su primera pieza en tres actos, los teatristas nacionales de la época notaron en sus obras una actitud crítica hacia el pasado nacional...» ${ }^{10}$.

Pero tales palabras establecen una oposición inexistente e innecesaria; no hay ningún conflicto lógico entre percibir tal actitud crítica en las obras más tempranas (la cual, obviamente, existe en un grado importante) y considerar que Asesinos es la, hasta entonces, culminación técnica de tendencias vistas de modo importante en dichas obras. Añade De la Campa que éstas

son consideradas meramente como esfuerzos preliminares que llegan a producir una síntesis certera en La noche... De esta visión se deduce que el trabajo previo de Triana ha sido más bien un período de desarrollo culminado por la última obra. Dos de los más recientes libros de crítica teatral latinoamericana reiteran y tienden a perpetuar esta tendencia: Ensayos sobre teatro hispanoamericano (1975), de Frank Dauster, y Dramatists in Revolt, The New Latin American Theater (1976), editado por Leon F. Lyday y George W. Woodyard.

Pues, dejando de lado que los dos ensayos citados no son sino uno publicado en español e inglés, cabe subrayar dos cosas. Primera, la palabra «meramente» no creo que se justifique, ya que en ningún momento dicho

${ }^{10}$ Román V. de la Campa, José Triana: Ritualización de la sociedad cubana (Minneapolis: Institute for the Study of Ideologies and Literatures, 1979), pp. 13-14. 
artículo desprecia el considerable valor de ese teatro. Segunda, negar la obvia superioridad de Asesinos a estas obras, por buenas que sean, parece responder a una actitud más bien relacionada con criterios extraestéticos.

Este hecho se constata en las palabras que dedica De la Campa a estas obras escritas antes de Asesinos: «No cabe duda que en ellas se hace una fuerte crítica a los gobiernos precedentes a la Revolución. Sin embargo, la incapacidad de superar o renovar esta temática, así como el uso de formas absurdistas, pusieron en duda el desarrollo posible de Triana de dramaturgo en Cuba. La realidad revolucionaria no se prestaba a ser captada por dichas formas estéticas...» ${ }^{11}$ Es decir, que esta obra no servía los propósitos del Gobierno, tal y como los interpreta el crítico. Esta clase de crítica prescriptiva y el fuerte tono político que empapa tanta crítica de Triana, conducen, a su vez, a unas curiosas perspectivas, muy variadas, sobre las obras tempranas y a una aún más curiosa resistencia, de parte de la crítica, a señalar las importantes coincidencias entre ellas y otras que surgen de la misma problemática, las obras ya comentadas de Brene y Felipe.

Estas semejanzas son inmediatamente obvias. En Medea en el espejo Triana sigue de cerca la tragedia de Eurípides; la diferencia principal es el descubrimiento mucho más paulatino de la traición de Julián. Como la Santa Camila, de Brene, la acción toma lugar en un solar, en vez del burdel, pero Julián, el mañoso amante blanco de María y, en el mejor de los casos, afiliado con el inframundo criminal, proyecta abandonarla para casarse con la hija del político corrompido Perico Piedra Fina. En su función dramática, los personajes corresponden de un modo muy cercano a los originales, pero también hay importantes adaptaciones, con el propósito de transformar el ambiente de la obra en una atmósfera inconfundiblemente cubana. Por ejemplo, la nodriza de Medea se convierte en la vieja criada negra Erundina, figura llegada directamente del folclore y el teatro popular, con sus refranes salpicados de ecos de Africa. Este manejo del idioma es uno de los aspectos más interesantes del drama, ya que María también habla, a veces, en un cubano cotidiano, que contrasta muy eficazmente con sus grandilocuencias más altisonantes. Rine Leal ha hablado de modo elocuente de este aspecto de Medea en el espejo, alabando la autenticidad de la obra. Señala de modo especial «...la integración que él ha logrado de los diversos elementos que componen nuestra realidad diaria (el solar, el ambiente, los tipos, su psicología, el mito afrocubano, la irrealidad de muchas de nuestras situaciones)...» ${ }^{12}$, y del tema de la mulata

\footnotetext{
1 De la Campa, Op. cit., p. 24.

12 En primera persona, p. 125.
} 
en concubinato con blanco, dice que es típicamente cubano ${ }^{13}$. Añade Leal que Triana cumple con su propósito «descubriendo en nuestros personajes populares la existencia de una realidad diferente e inesperada». "Hay en esta tragedia del "que dirán" solariego una realidad diaria, manejada estupendamente por el autor, compuesta de estampas de costumbres y tipicismos del habla popular, junto a la realidad mágica de la Medea original con su idioma poético» ${ }^{14}$.

No faltan tentativas de hacer de este proceso de anclar la anécdota en una realidad específica, algo así como una analogía a la historia cubana. De la Campa identifica a Perico con el período republicano, probablemente con razón; pero de ahí saca unas conclusiones que vale la pena reproducir aquí:

... esta pieza es la única que sugiere, como resultado de la ritualización, cierto rompimiento de las cadenas sociales opresivas... Con el asesinato de sus hijos, cuyo padre es blanco y la había traicionado, el acto criminoso de Medea plantea una emancipación racial y social. La violencia toma un fin purificador... (p. 26).

En el plano colectivo histórico cubano que representa Perico, esta destrucción de su mundo constituye una apertura para la renovación. Las etapas de barbarie política, caracterizadas en la obra desde la independencia hasta la dictadura batistiana a través de este personaje, quedan simbólicamente eliminadas y desprovistas de una descendencia humana con la muerte de los hijos de Julián. El prejuicio y la humillación sufridos por las razas negras y mulata adquieren reivindicación también con la muerte de ellos. El mestizaje cubano, es decir, la raza mulata cobra un sentido de valor y orgullo que transforma el servilismo y la inferioridad sentidos por María, sus compañeras y los personajes del coro ante la blancura de Julián y Perico, en un sentimiento heroico y exaltante. Esto hace de Medea en el espejo una obra de dimensiones renovadoras en el repertorio de José Triana (p. 15).

Si reconocemos la concentración de la obra en María, estas aseveraciones parecen exageradas, y resulta difícil ver en la masacre al por mayor de niños indefensos alguna clase de renovación.

En todo el teatro de Triana se halla un claro doble enfoque: el social y el individual, polaridad a la cual se ha dirigido el mismo autor en diversas ocasiones. Al volver a Cuba, en 1959, encontró «... una actitud crítica, una crítica al pasado, a todo lo que se había vivido. Entonces, eso me movió fundamentalmente y me decidí a escribir... Partiendo de aquel mundo con un sentido crítico, aquel mundo me fue dado. Yo soy un

\footnotetext{
${ }^{13}$ Idem, p. 126.

14 Idem, p. 175.

${ }^{15}$ José Triana: Ritualización de la sociedad cubana, op. cit., p. 58.
} 
testigo, lo sufrí. Y testificar es más bien desgarrarse. Esa es la verdad» ${ }^{16}$. Lejos está esto de querer sugerir que Triana, como Brene, está comprometido con un teatro que en lo fundamental se orienta hacia lo exterior. Reconoce Triana la naturaleza esencialmente social del teatro, pero dentro de dicha naturaleza social es de importancia primordial el individuo:

El teatro siempre es social, puesto que expresa, mejor o peor, como absoluto o parte, la realidad de una sociedad, de un pueblo. El teatro necesita del hombre, que es al mismo tiempo vehículo conductor y receptor. Sin él no existe. Por tanto, el teatro es el hombre. ¿No sería un lugar común decir que el hombre es un ser social por excelencia? [...] El escritor camina casi siempre de lo particular a lo general. He ahí la premisa inconsciente, viva, insoslayable. No creo que exista una ruptura entre lo vernáculo y lo universal ${ }^{17}$.

En este sentido, el teatro de Triana es auto-referencial, vuelto hacia adentro para tratar situaciones humanas. Como Felipe, lucha por ver y comunicar esas pequeñas epifanías que otorgan algún grado de significado a vidas que en la superficie carecen de toda dignidad:

Yo me propongo como autor realizar en cada obra una aventura, una posible aventura del espíritu común del hombre, del hombre en su raíz, en sus hechos. Descubrir los secretos, la vida misteriosa, extraña, apasionada. Es decir, los recuerdos, las pesadillas, todo incorporado en el escenario, como formando una gran realidad que es la realidad teatral $[\ldots]^{18}$... yo busco al hombre en un desafuero, en una pasión, en un acto de violencia ${ }^{19}$.

Pero en el caso de Triana, como en el de cualquier dramaturgo, trazar distingos entre estos dos niveles de teatro no hace sino falsificar la naturaleza esencialmente totalizante de la obra:

... si no hubiera sido por ese pasado sórdido, no tendríamos hoy lo que tenemos. Es decir, mis obras plantean y justifican desde el punto de vista del arte nuestra vida actual. No tengo el propósito de hacer panfletos, sino mirar, ahondar, ahondar en nosotros mismos, en nuestras lacras, el sentido del mal, la crueldad. Esa descomposición que se vivió y que hizo posible, abrió una ventana, abrió una puerta, abrió un camino para el mejoramiento de nosotros mismos.

${ }^{16}$ Triana y otros, «El teatro actual», Casa de las Américas (IV, 22-23, enero-abril 1964), p. 105 .

17 «El nuevo teatro cubano», p. 7.

$18 \ll$ El teatro actual», loc. cit., p. 100.

$19 \ll$ El teatro actual», p. 103. 
A mí me interesa ahondar en mí mismo y en los demás para dar una medida de lo que somos ${ }^{20}$.

No cabe duda de que, a pesar de los esfuerzos por hacer de Medea y otras obras de Triana documentos sociales, su concentración principal es individual, un esfuerzo por encontrar significado humano y forma trágica en los niveles más abandonados de la sociedad. La dimensión social de Medea radica en la subversión del orden mediocre establecido y la demostración de que aun en este nivel la gente es capaz de la verdadera pasión trágica.

Aún más firmemente anclado en este mundo sórdido es La muerte del Neque; despide un aire de amenaza y abyección de una manera que las otras obras apenas pueden sugerir. El título se refiere a la figura folclórica popular del Neque, quien trae la mala suerte y la maldad. Hilario, el Ñeque del título, es funcionario importante, tanto de la policía como del hampa habanera. La anécdota de la obra, como de las otras que comentamos aquí, es realmente bastante sencilla: Juvencio, hijo de una víctima de Hilario, conspira para matarlo y seducir a su amante, Blanca Estela. Hay una historia secundaria que repite las mismas relaciones: a Pablo, hijo de Hilario con su primera mujer, lo ama la criada Berta, pero Pablo está fuertemente atraído por Blanca Estela, quien, a su turno, coquetea con él. En el apogeo de su poderío brutal y de su fe en su propia fuerza y en la buena suerte que lo favorecía, descubre Hilario que no recibirá el ascenso que le habría proporcionado aún más influencia y riquezas. Rompe con Blanca Estela y Pablo, y muere asesinado.

La muerte del Ñeque es una obra impresionante, la tragedia de un hombre que cae por el más absoluto azar, como podemos caer todos. Se compensa la sencillez de la historia con la lenta inexorabilidad de su desarrollo y por el empleo abierto de las convenciones de la tragedia clásica. Toda esta armazón la sostiene el empleo ritualizado de los tres asesinos: Nico, Juan y Pepe. Son simultáneamente coro, hado y verdugos del desventurado Hilario. Son constantes el diálogo ritualizado y el aparato del azar — dados, billar, juegos de niños- en un anticipo brillante de $L a$ noche de los asesinos, y la palabra «juego» se emplea como motivo a través de toda la obra. A la vista de esta complicada estructura formal, parece erróneo asumir para La muerte del Neque la referencialidad histórica absoluta propuesta por algunos críticos. Es más bien otro paso en el desarrollo, por Triana, de un teatro esencialmente trágico, que demuestra la fragilidad y la violencia irracional de la existencia humana.

\footnotetext{
${ }^{20}$ «El teatro actual», p. 104.
} 
Si ahora examinamos juntas las cuatro obras, vemos un número realmente impresionante de semejanzas. En un plano puramente narrativo, todas tratan de crímenes especialmente sensacionales: María despacha sangrientamente a sus hijos con Julián, y a Perico y su hija; a Yarini lo asesinan Lotot y/o sus pistoleros, Hilario muere literalmente carneado por los tres asesinos. Los ambientes son punto menos que idénticos: Brene y Felipe ubican sus obras directamente en el distrito de los burdeles. La muerte del Neque rezuma corrupción y vicio, y la atmósfera de Medea en el espejo es de sordidez y avaricia casi sin descanso. Dos obras toman lugar directamente en burdeles, otra en un solar que no dista mucho de serlo, la cuarta en una región nebulosa que representa un ambiente generalizado. Tres de las figuras femeninas más importantes son abiertamente prostitutas, mientras que María parece tener una historia muy cercana a la prostitución. En las cuatro obras predomina un aire de erotismo sobrecargado. Además de los burdeles de Brene y Felipe, María está obsesionada por la carnalidad de Julián, y La muerte del Ñeque está empapada de sexualidad. Blanca Estela provoca a Juvencio y a Pablo, Berta coquetea con Pablo y Blanca Estela y Juvencio se abrazan abiertamente en el balcón antes de entrar, mientras que los asesinos juegan a su billar sugestivo. Hay otra nota intrigante en El gallo de San Isidro: los grupos respectivos de chulos franceses y cubanos suelen consistir en tres miembros, posible eco del empleo frecuente de tales tríadas en Triana.

En este mismo sentido, las cuatro obras tratan relaciones triangulares $-\mathrm{y}$, a veces, aún más complicadas - que conducen directamente al desenlace desastroso. En su raíz, las cuatro representan las consecuencias de un amor enloquecido. O quizá fuera más exacto decir de un amor que empuja al amante a romper el código según el cual aceptó vivir. Ciertamente, que Yarini haya amado a una de sus prostitutas constituye una ruptura grave del código del chulo, y en las dos obras que tratan sobre Yarini es este hecho lo que le conduce al desastre, más que todas las conspiraciones del palacio presidencial. María aceptó vivir su papel dentro de las estructuras sociales que gobernaban su tipo de existencia, y su irrupción apasionada, por justificada y libertadora que fuera, todavía constituye una ruptura del código. El caso de La muerte del Ñeque es algo distinto, puesto que aquí Hilario no es realmente el personaje central en términos de los mecanismos técnicos de la obra. Su asesinato es el resultado más bien de la sed de venganza de casi todos los otros personajes, con el incentivo añadido de la pasión adúltera de Juvencio y Blanca Estela. En las cuatro obras, el juego es una causa dramática importante.

Otra preocupación característica de los tres dramaturgos es la cubanía, lo cual dista mucho de la sencilla insistencia en el color local o el costum- 
brismo. José R. Brene lo formula muy claramente al afirmar que de todos los dramaturgos cubanos anteriores a su propia obra prefiere a Carlos Felipe: «Porque encuentro en su teatro, en sus personajes, un fuerte espíritu de cubanía, porque Carlos Felipe tiene ojos para ver lo que realmente es cubano... De los dramaturgos extranjeros, el que más me interesa es Ramón del Valle-Inclán. Mi mayor anhelo es llegar a trazar los personajes de mi tierra con tanta fuerza y verdad como él supo trazar los de su tierra» ${ }^{21}$. Tanto Felipe como Brene, en vez de hacer un teatro europeo importado, llenan sus obras del habla cubana, ambientes cubanos y hasta estrictamente habaneros, tipos populares cubanos, en un esfuerzo por captar la esencia de su gente y de sus problemas. De la misma manera, los personajes de Medea y Neque son cubanos en su lenguaje, en su ubicación, en el choteo de sus reacciones. Todo esto está relacionado directamente con un elemento primordial que comparten las cuatro obras a un grado importante: la herencia africana. Las relaciones amorosas suelen expresarse en términos simbólicos de esta herencia: Medea es mulata, Julián blanco, Hilario y Berta son mulatos, Blanca Estela y Pablo, blancos.

Estas relaciones simbólicas se extienden a los personajes mı nores: los tres asesinos de Hilario son un blanco, un negro y un mulato. Con los demás, representan el complejo mundo multiétnico, con toda su injusticia institucionalizada, en el cual funcionan María, Hilario y Yarini. Y no es que este componente africano sea cosmético ni postizo; constituye una parte nuclear de la estructura de las diversas obras. Cita Matías Montes Huidobro a Réquiem, Camila y las dos obras de Triana como piezas en las cuales «lo afro queda integrado a la problemática cubana» ${ }^{22}$. José Escarpanter va mucho más allá, al afirmar que Réquiem alcanza estatura mítica y trágica porque Felipe contrasta la acción de «las rivalidades de Yarini y Lotot por la hegemonía de la zona prostibularia y la Santiaguera y las amenazas de la campaña de moralización nacional anunciada por el Gobierno, y otra, desarrollada en el plano supraterreno, planteada según los principios de la religión yoruba, politeísta y antropomórfica como la de griegos y romanos, donde se producen violentas peleas entre las divinidades y en las que éstas pueden salvar o contribuir a la destrucción de los mortales» ${ }^{23}$. Esta interpretación de la importancia del trasfondo africano ve a la Macorina como la fuerza que desencadena los episodios para que se unan ella y Yarini, y a figuras menores, como Bebo, la Raposa y la

${ }^{21}$ «El nuevo teatro cubano», p. 4

${ }_{22}$ Persona: vida y máscara en el teatro puertorriqueño (San Juan: Centro de Estudios Avanzados de Puerto Rico y el Caribe, Ateneo Puertorriqueño, Universidad Interamericana, Tinglado Puertorriqueño, 1986), p. 138.

${ }_{23}$ «Réquiem por Yarini, de Carlos Felipe: una tragedia cubana», p. 106. 
Jabá, les asigna papeles equivalentes a un sacerdote y a la pitonisa Casandra, respectivamente.

Conducen tales interpretaciones a reconocer un parecido mucho más básico entre los cuatro dramas: la insistencia de los tres autores en tratar a sus protagonistas en términos míticos, lo cual no es lo mismo que decir que los tratan de la misma manera. En su estudio detenido de la polaridad entre Brene y Felipe dice Montes Huidobro de El gallo de San Isidro y Réquiem por Yarini: «los autores siguen dos perspectivas opuestas significativas: Idealización vs. desidealización del mito» ${ }^{24}$. En el mismo libro califica a la obra de Felipe de mito erótico de sexo y magia negra (p. 303) y a su protagonista como símbolo fálico trascendente (p. 306). El desdén de Montes Huidobro por la campaña política de Brene es tan obvio como divertido, como cuando habla, con alguna exageración pero mucha justicia, de cómo maneja Brene el clisé de la prostituta honrada que se niega a acostarse con Yarini porque lo quiere. «Brene se ha propuesto crear el anti-Réquiem por Yarini. Si aquella obra nos ofrecía el culto al sexo, ésta tenía que oponerse y volverse anti-sexo. El sexo masculino es aniquilado por la anti-chulería de la obra; el femenino, por este personaje femenino, que poco falta para que la haga virgen» ${ }^{25}$.

Otros críticos han visto igualmente esta creación mítica en la obra de Felipe; Escarpanter cree que cabe aplicarle a Yarini la teoría de Jung de que «el mito es una expresión de los arquetipos del inconsciente colectivo. Yarini, sin discusión, puede elevarse a la categoría de mito nacional» ${ }^{26}$. En el mismo lugar señala Escarpanter las ambiciones trágicas de Felipe; como Oedipo, Hamlet, Phaedra y Willi Lohman (sic), el Yarini de Felipe «ostenta una psicología ambivalente..., lucha contra fuerzas superiores a sus posibilidades, comete un error o falta, la famosa "hamartia" de los griegos y finalmente resulta vencido, pero en este fracaso hay una especie de reconocimiento, glorificación o plenitud». Concepción T. Alzola va aún más allá cuando comenta los sorprendentes paralelos bíblicos y mitológicos:

Dejaremos a un lado el análisis de las superposiciones (Yarini - chulo criollo-, souteneur; Cristo, Osiris, Adonis - por su relación con la Jabá Rea-y un dios indeterminado. Dimas, buen ladrón, a la puerta del Paraísoballú privado de Yarini, en figura de un negro del Manglar. La persecución de la policía habanera, que desata un Getsemaní. El oráculo consultado a comienzos de la obra, un tablero de Ifá. O la apoteosis de Yarini, arrebatado

\footnotetext{
${ }^{24}$ Persona, vida y máscara en el teatro cubano (Miami: Edics. Universal, 1973), p. 284.

${ }^{25}$ Idem, p. 311.

26 «Réquiem por Yarini, de Carlos Felipe: una tragedia cubana», p. 105.
} 
en un carro nupcial, del brazo de la Macorina, mencionando sólo las más evidentes)... ${ }^{27}$

Sugiere Natividad González Freire que domina en toda la obra la presencia de la muerte como «el personaje clave, el invisible, el que define la atmósfera, la poesía y la verdad de su protagonista» ${ }^{28}$. Esta perspectiva hace hincapié en la importancia del azar, el juego al cual pierde a Lotot: «En acto luminoso de creación hace depender el porvenir de Yarini de un juego de signos cabalísticos: la charada criolla».

Brene, por supuesto, no intenta nada parecido a esta semidivinización de Yarini. Cabe sospechar que habría preferido desterrar tanto al personaje como a lo que representa. Curiosamente, no obstante, el tratamiento de Yarini por Brene, mientras teóricamente lo desmitifica, lo trata en términos muy parecidos a como lo trata Felipe. Es decir, lo presenta como individuo en contraposición a sus acciones políticas y criminales. Vale decir: mientras Brene busca mostrar que el mal social de la prostitución y la corrupción que engendra deben ser borrados de la sociedad, a la figura de Alejandro Yarini lo sigue romantizando al punto de mitificar o mitologizarlo. Con mucha razón señala Montes Huidobro el impacto higiénico de la versión de Brene, pero todos los comentarios moralizantes de los personajes sobre el mal que han hecho no quita el hecho de que «el gallo de San Isidro», individual y personalmente, sigue ejerciendo su magnetismo sobre los personajes y su autor.

Medea en el espejo, como La muerte del Ñeque, como El gallo de San Isidro y Réquiem por Yarini, como La noche de los asesinos, todas son representaciones ritualizadas de un asesinato. Además, sus víctimas tienden a ser más bien chivos expiatorios que verdaderamente culpables. En este nivel, el Yarini de Brene no es más que otro de los funcionarios medianos que realizan los inicuos esquemas de los principales políticos y sus aliados extranjeros. Lo asesinan en una conspiración política para encubrir la identidad de los verdaderos responsables. El Yarini de Felipe, por supuesto, nada tiene de culpable. Por lo contrario, hasta parece creer que desempeña un servicio público importante, de modo que resulta aún más el chivo expiatorio, víctima de una componenda, que el protagonista de Brene. Obviamente, ningún lector en sus cabales puede considerar que los niños víctimas de la furia de María, en contraste con el hondamente repugnante Perico Piedra Fina, son otra cosa que inocentes masacrados porque no tiene María otra forma de expresar su furor. Cargan con el fardo de un

27 «Lectura de Yarini», en Alberto Gutiérrez de la Solana y Elio Alba Bufill, eds., Festschrift José Cid Pérez (Nueva York: Senda Nueva de Ediciones, 1981), p. 111.

28 «Sobre dramas y dramaturgos», Unión (VI, 4, dic. 1967), p. 240. 
sistema social y personal manifiestamente injusto, pero del cual ellos mismos son totalmente inocentes. Hilario García lo es en grado menor; es, después de todo, un funcionario público corrompido y un criminal. Pero Hilario es una figura intrigante. En primer lugar, no comprende en absoluto lo que le pasa; no hay percepción alguna, ni siquiera de lo que fue en su vida y en su muerte. Segundo, aunque domina toda la obra la sombra de Hilario, es en rigor un personaje relativamente menor y en quien sólo aparece bien desarrollada la acción de la obra. Las figuras verdaderamente dominantes son los tres asesinos, los hados o el destino, porque son las tres cosas a la vez. Son también el mito del mal. Si acaso Asesinos capta mejor la naturaleza de doble filo de esta violencia, en ningún otro lugar del teatro de Triana hallamos exposición más clara de esta maldad.

Más todavía: las cuatro obras ensayan crear una acción trágica alrededor del personaje principal. Ya vimos como Medea en el espejo y La muerte del Neque participan también en esta mitificación de una manera estrechamente ligada a la búsqueda de una estructura trágica. Cuando los personajes de la tragedia clásica reconocen su culpa, los dioses les imponen el castigo o les otorgan la purificación, pero los personajes de Triana tienen que seguir sin culpa ni redención. En un nivel cósmico, han sido abandonados. Felipe intentaba crear la tragedia de su protagonista mitificado, mientras Brene, quizá por la misma naturaleza de su material dramático, quizá porque a pesar de su intención expresa se sentía atraído por su protagonista carismático, parece haber sido forzado a emplear una concepción dramática que utiliza las mismas convenciones estructurales. Ni Brene ni Felipe tienen éxito en ahondar mucho más allá del nivel superficial; a pesar de las alabanzas que muchos críticos dispensaron a Réquiem por Yarini, debilitan el desarrollo y la concentración dramática los graves problemas creados por el diálogo retórico y la intrusión de la Dama del Velo y el episodio de la Macorina.

Las cuatro obras están esencialmente arraigadas en la realidad cubana. Como hemos visto, los autores buscaban de modo consciente crear una expresión dramática de la cubanía. Tanto para Felipe como para Brene, el referente externo es también mucho más; en los dos casos, Yarini y su mundo representan el período de la República. Al decir de Natividad González Freire: «Asimismo, el barrio de San Isidro trasciende su condición de sitio de prostitución para devenir tablado donde, en circunstancias cubanas, se confrontan pasiones comunes a todos los hombres. La muerte de Yarini no es la simple de un crimen político o de una reyerta entre chulos, sino la destrucción de una leyenda» ${ }^{29}$. Una de las dificultades

${ }^{29}$ Idem, p. 240 
considerables de ambas visiones del mundo habanero criminal de 1910 es, pues, que en los dos casos están al servicio de consideraciones extrateatrales. Donde Brene condena sin vacilación la República, Felipe obviamente busca algo que, si no la justifica, por lo menos la explique. Lo hace mitificando abiertamente la figura del personaje principal, intentanto crear conscientemente una figura trágica. La intención de Brene, por otro lado, es didáctica, y no sólo condena la República: quiere, en nombre de la Revolución, destruir el mito de Yarini y la destrucción de todos los males sociales.

El teatro de Triana también está radicado en la realidad de Cuba, pero de una manera diferente y menos superficial. Al hablar de La noche de los asesinos, dijo: «Esta es una obra que yo no hubiera podido escribir si no hubiera vivido la Revolución... La noche de los asesinos es una obra que escribo precisamente porque poseo la conciencia nacional. La conciencia nacional que la Revolución le ha dado a nuestro pueblo y por la que nuestro pueblo ha podido seguir hacia adelante» ${ }^{30}$. Medea en el espejo y La muerte del Neque tratan una difícil situación cubana, una circunstancia social típica, tan típica que, como hemos visto, atrajo también los esfuerzos de otros dramaturgos. Pero éstos enfocaron sus obras, cada cual por su lado, hacia la narrativa de superficie. Las obras de Triana presentan una sociedad opresora y racista, pero trascienden este plano para examinar también estructuras internas humanas que no quedan restringidas a un lugar o un tiempo. La mayoría de las características comunes a las dos obras más tempranas son ciertas también en La noche de los asesinos. Aunque no vienen al caso aquí, habría que notar que el conflicto generacional medular de La noche de los asesinos es también central a La muerte del Neque, y la búsqueda de una vida auténtica a través del autodescubrimiento, tan notable en La noche de los asesinos, es también el eje de la trayectoria de María en Medea en el espejo. Si La noche de los asesinos es una obra maestra, también merecen las otras dos obras más atención crítica de la que han recibido.

${ }^{30}$ «José Triana habla de su teatro», Románica, 15 (1979), p. 39. Citado por Priscilla Meléndez, «El espacio dramático como signo: La noche de los asesinos, de José Triana», en Latin America Theatre Review (17/1, Fall 1983), p. 29. 